\title{
Changing emergency department and hospital organization in response to a changing epidemic
}

\author{
Daniele Coen, Ciro Paolillo, Mario Cavazza, Gianfranco Cervellin, Andrea Bellone, \\ Stefano Perlini, Ivo Casagranda
}

Academy of Emergency Medicine and Care (AcEMC)

The world is facing a new pandemic that sets the national health systems, their structures and professionals in a crisis never experienced before. More than 500 articles on COVID-19 have already appeared in international medical literature, suggesting that the SARS-CoV-2 virus will be much more difficult to contain than those responsible for SARS and MERS, ${ }^{1,2}$ at least for two reasons. The first, its Reproductive Rate (RR) is 2-3 people per infected patient, the disease is therefore transmitted very efficiently and its incidence has an exponential trend. The second, it has a high mortality, between 1 and 3\% (with a rate even 3-4 times higher in the elderly) and, according to Chinese estimates, ${ }^{3}$ an important amount of severe $(14 \%)$ or critical cases $(5 \%)$.

The combination of these two aspects jeopardizes the tightness of health facilities and requires a reorganization of the Emergency Department (ED) and the hospital as a whole. In fact, the COVID19 epidemic requires the activation of an Internal Emergency Preparedness Plan which has a greater complexity than a usual one, as it is characterized by repeated waves of accesses for a period the end of which is not yet foreseeable. Figure 1 shows the data related to ED accesses and hospital admissions for COVID-19 in the first two weeks of March (from the $1^{\text {st }}$ to $8^{\text {th }}$ ) at the University Hospital of Brescia, a large hub of Lombardy. Interestingly there is an accesses reduction but a constant admission of COVID-19 patients.

Italy, and especially the districts of Lombardy, Veneto and Emilia Romagna, are the center of the second epidemiological outbreak in the world and, although only three weeks have passed since the first case appearance, the number of infected and severely ill patients is already so prominent that a significant experience has been accumulated in the management of the problem. We believe that sharing this knowledge and the open questions could help those who are operating in the initial epidemic stage, but could find themselves facing the critical issues within a short time.

Correspondence: Ivo Casagranda, Academy of Emergency Medicine and Care (AcEMC), via Salvatore Maugeri 10, 27100 Pavia, Italy

E-mail: casagranda.senior@gmail.com

Received for publication: 16 March 2020.

Accepted for publication: 16 March 2020.

This work is licensed under a Creative Commons Attribution 4.0 License (by-nc 4.0).

${ }^{\circ}$ Copyright: the Author(s), 2020

Licensee PAGEPress, Italy

Emergency Care Journal 2020; 16:8969

doi:10.4081/ecj.2020.8969
We will therefore examine the main clinical and organizational aspects of this epidemic, with particular attention to ED's work.

In any case, you will have to pursue the following objectives as a priority:

i) Maintaining a response as efficient as possible to all patients with urgent conditions (e.g. acute myocardial infarction, stroke, trauma etc.) or with other serious pathologies. This includes the need for the hospital as a whole to be able to continue the surgical management of cancer, cardiovascular diseases and more in general patients needing short-term surgery;

ii) an adequate clinical response to patients with COVID-19 respiratory problems, both in ED and in-hospital;

iii) adequate logistical, administrative, technological and personnel support that allows professionals to follow protocols safely and in the best possible way.

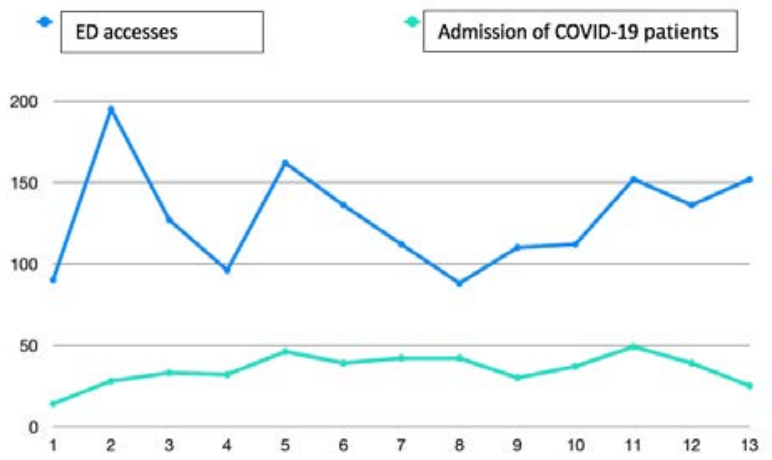

Figure 1. ED accesses and admission of COVID-19 patients from ED. 


\section{The hospital should operate for every type of patient}

The first consequence of this proposition is that each hospital should provide two parallel and non-intersecting paths, named COVID-19 and clean path respectively, starting from the first patient ED access. Although ED represents the main entrance door to hospital, a careful anamnestic and objective screening is also necessary for all patients accessing directly to internal wards, to avoid the risk of clean pathways contamination, event unfortunately already reported. A second consequence is to carefully balance the distribution of spaces and resources between the two paths.

The elevated number of patients with COVID-19 pneumonia force to devote these patients to hospital departments previously intended for something else. In the districts of Lombardy, Veneto and Emilia Romagna beds for minor non-urgent surgery have often been reserved for COVID-19 patients' admission. Even major surgery is at risk of decelerating because of the reduced availability of intensive or sub-intensive care beds, which are today under a stress-test by the epidemic serious respiratory forms. Within the limits granted by the availability of health professionals and equipment, the increase of intensive care beds is certainly the major step to ensure treatment and safety to patients with critical or severe problems not related to the epidemic. With the increasing number of COVID 19 cases and hospitalized patients, the decision-makers reacted centralizing non-infectious emergency management (traumatological, neurological and cardiovascular) in hub hospitals, dedicating other hospitals almost exclusively to infected patients. Beds in private hospitals neither equipped with ED, nor usually dedicated to the treatment of complex patients, have also been made available to infected patients with mild or moderate illness.

\section{An adequate ED clinical response}

In most EDs a pre-triage has been arranged outside the hospital with special field tends. The pre-triage task is to differentiate patients with symptoms possibly related to COVID-19 (fever, cough, contact with infected subjects) from those without these characteristics. The subsequent triage should already be physically separated for the two paths (infectious and non-infectious) thus also reducing length of stay in an often-crowded area.
The triage of COVID-19 suspected patients should aim to distinguish them into some severity classes. The Lombardy hospitals have chosen to divide the patients into five phenotypes based on the respiratory impairment level and chest X-ray findings (Table 1). A definite organizational advantage was allowing nurses to perform an arterial blood gas and to request a chest X-ray (in dedicated radiology) before referring patients to the emergency physician. A further level of nursing assessment recognized important in dividing patients by class severity is the modification of basal pulse oximetry values after a walking test ( 30 meters at the fastest possible pace) and, in the most severe cases, after a few minutes of oxygen treatment in a non-rebreathing oxygen mask at 15 liters per minute.

In a clinical context, a pharyngeal and nasal swab is helpful only for patients with minor symptoms (phenotypes 1 and 2) since it may help to distinguish patients with SARS-CoV-2 infection from patients with other viral respiratory infections. In the most severe cases, as documented by the Chinese experience, clinical and imaging features may be all that is needed to identify patients with COVID-19. Chest Computed Tomography (CT) has a high sensitivity for SARS-CoV-2 pneumonia ${ }^{4}$ although, in front of a high number of accesses, chest X-ray may be an adequate screening tool for patients' triage. A CT scan should nevertheless be performed in patients with highly suspected symptoms and a normal $\mathrm{X}$-ray. Where emergency doctors are skilled in bedside sonography, lung ultrasound can be used for screening patients and monitoring pulmonary involvement in the short time. Beyond a first comprehensive routine panel and an arterial blood gas, there seems to be no advantage in repeating blood tests in the ED, pulse-oximetry being the only useful parameter to be monitored over time.

High flow oxygen therapy and Non-Invasive Ventilation (NIV) are currently used for patients not responding to conventional oxygen therapy as a bridge to tracheal intubation. ${ }^{5}$ There are no shared guidelines for the use of these techniques in severely hypoxemic patients and their parameters should be adapted to each patient's clinical picture. When using these forms of ventilatory support, be aware of the possibility of respiratory parameters quick worsening and the need for prompt tracheal intubation. Moreover, these noninvasive techniques rise the risk of aerosolized virus diffusion in healthcare environment, such as in the setting of a poorly fitting face mask.

When ED access is high, patients with COVID-19 respiratory failure should stay just as long as necessary for an adequate clinical

Table 1. Proposed COVID-19 clinical classification for patients' triage.

\begin{tabular}{|c|c|c|c|c|}
\hline Phenotype 1 & Phenotype 2 & Phenotype 3 & Phenotype 4 & Phenotype 5 \\
\hline Fever AND/OR & $\begin{array}{l}\text { Single opacity at chest X-ray } \\
\text { AND/OR }\end{array}$ & $\begin{array}{l}\text { Multiple opacities at chest } \\
\text { X-ray AND }\end{array}$ & $\begin{array}{l}\text { Multiple opacities at chest } \\
\text { X-ray AND }\end{array}$ & $\begin{array}{l}\text { Multiple opacities at chest } \\
\text { X-ray AND }\end{array}$ \\
\hline $\begin{array}{l}\text { Respiratory } \\
\text { symptoms AND }\end{array}$ & $\mathrm{SpO}_{2} 90-94 \% * \mathrm{AND} / \mathrm{OR}$ & $\mathrm{SpO}_{2}<90 \% *$ BUT & $\mathrm{SpO}_{2}<90 \%$. BUT & $\mathrm{SpO}_{2}<90 \%$. AND \\
\hline $\begin{array}{l}\text { Normal chest } \\
\text { X-ray AND }\end{array}$ & $\begin{array}{l}\text { Walking test } * * \\
\text { desaturation }\end{array}$ & $\begin{array}{l}\mathrm{SpO}_{2}>94 \% \text { in } \\
\text { oxygen } 15 \mathrm{~L} / \mathrm{min} \\
\text { with reservoir }\end{array}$ & $\begin{array}{l}\mathrm{SpO}_{2} 90-94 \% * \text { in oxygen } \\
15 \mathrm{~L} / \mathrm{min} \text { with reservoir } * *\end{array}$ & $\begin{array}{l}\mathrm{SpO}_{2}<90 \% \text { in oxygen } \\
* * * 15 \mathrm{~L} / \mathrm{min} \text { with reservoir }\end{array}$ \\
\hline $\begin{array}{l}\mathrm{SpO}_{2}>94 \% * \text { AND } \\
\text { Walking test **: } \\
\text { no desaturation }\end{array}$ & Treat with $\mathrm{O}_{2}$ to $\mathrm{SpO}_{2}>94$ & Treat with $\mathrm{O}_{2}$ to $\mathrm{SpO}_{2}>94 \%$ & Treat with CPAP & $\begin{array}{l}\text { Perform tracheal } \\
\text { intubation as soon as possible }\end{array}$ \\
\hline $\begin{array}{l}\text { Send home with } \\
\text { information sheet }\end{array}$ & Control within 6 hours & $\begin{array}{l}\text { Admit to sub-intensive care } \\
\text { Control within } 6 \text { hours }\end{array}$ & $\begin{array}{l}\text { Admit to sub- } \\
\text { intensive/signa } \\
\text { to intensive care } \\
\text { Control within } 6 \text { hours }\end{array}$ & Admit to intensive care \\
\hline
\end{tabular}

* $\mathrm{SpO}_{2}$ cut-offs may be lower for patients with COPD; **Walking test: get the patient's baseline $\mathrm{SpO}_{2}$ then have him walk at the maximum possible speed for approximately 30 meters. The test is positive for a drop in $\mathrm{SpO}_{2}>3 \%$; ***Patients' clinical conditions and respiratory patterns are often good compared to their arterial gas values, yet appropriate treatment should not be deferred. 
evaluation and admission to an appropriate level of care ward. This in order to free up space and personnel for new arrivals. All tests of dubious value should be avoided.

\section{Crisis management and logistic support}

An epidemic of such magnitude as the one that is sweeping the world nowadays establishes firstly important ethical problems. The main Italian anesthesiology scientific society has released a position paper defining criteria for admission to intensive care beds in a situation of limited resources. ${ }^{6}$ Co-pathologies and age are considered as potential reasons to withheld tracheal intubation. Not everything to everybody then, but just the minimum necessary, as far as possible.

Ventilators, individual protection equipment, oxygen and disinfectants are lacking but it is human resources that set the biggest problems. Doctors, nurses and technicians should be given the utmost protection to avoid contagion. An elevated number of infections among doctors and nurses were contracted during the first phase of the epidemic, when the use of individual protection equipment might have been less stringent. It is important to spread awareness in the areas with a low disease incidence so that their professionals adopt measures that guarantee a high protection level from the start. It is fundamental that the number of health professionals fighting the epidemic be adequate so that the infected ones can be substituted, and that everybody may enjoy rest pauses, which become more and more necessary with the persistence of the epidemic. In order to support the hospital staff, in the districts of Lombardy, Veneto and Emilia Romagna, doctors are now being recruited regardless of their specialty.

It is crucial for every hospital to have in place a Crisis Management Committee (CMC), active 24/24 hours and constantly communicating with regional and national authorities. Health, as well as administrative, informatics, and procurement expertise must be represented within the committees. CMCs are in charge of sharing the information, and of the timely procurement and distribution of supplies. They are also responsible for rapidly adapting hospital organization to the epidemic evolution and to the central authorities' directives. A third task for the committees is to safeguard as much as possible patients with serious conditions not related to the epidemic. Priority lists for access to general and specialty surgery as well as to outpatient clinics should be re-evaluated, and all non-urgent cases should be deferred. This has been done in the highly affected areas of Italy, allowing to shift a considerable number of professionals to the COVID-19 patients care.

\section{Conclusions}

The extremely rapid evolution of the COVID-19 pandemic is such that much of what is written in this editorial could be overtaken by events by the time of its publication. Nevertheless, we feel it is paramount to convey a message to the professionals of the least affected areas of our country and of the world: they should get ready and prepared from this precise moment, without wasting time before adopting all the measures which are necessary to slow the evolution of the SARS-CoV-2 epidemic. Moreover, there are some important points that we should carefully consider when the epidemic will come to an end. Firstly, we should reconsider the very sectorial education of Italian doctors. COVID-19 has forced many physicians to realize that, before training as a specialist or a sub-specialist, they should master the basic skills that every medical doctor should possess, and refresh over time. A prolonged attendance at emergency room and general medicine should possibly be considered as a requirement for physicians submitting any specialty school.

Secondly, we should appreciate the vital role that nurses are playing in the fight against SARS-CoV-2. Their autonomy in triaging and starting the first treatment of patients accessing overcrowded EDs is paramount in saving time and lives. The pitiless and narrow-minded defense of corporative interests that some associations of physicians maintain should be definitively overcome and nurses should be recognized for their high level of education and competence.

Thirdly, we should reflect about the very significant reduction in all-cause access at the EDs, which is now over 50\% in many Italian hospitals. Although more detailed information is needed, this seems to highlight how EDs were overused up to a few weeks ago. The response to minor and self-limiting ailments should be redirected outside the hospital. COVID-19 is going to drain a huge amount of money from the health system. In the future, we should be much more careful in allocating public money to the treatment of those who need it most.

\section{References}

1. del Rio C, Malani PN. 2019 Novel Coronavirus - Important information for clinicians. JAMA 2020.

2. del Rio C, Malani PN. COVID-19 - New Insights on a rapidly changing epidemic. JAMA 2020.

3. Wu Z, McGoogan JM. Characteristics of and important lessons from the Coronavirus disease 2019 (COVID-19) outbreak in China. Summary of a report of 72314 cases from the chinese center for disease control and prevention. JAMA 2020.

4. Kanne JP, Little BP, Chung JH, et al. Essentials for radiologists on COVID-19: An update - radiology scientific expert panel. Radiology 2020.

5. Ñamendys-Silva SA. Respiratory support for patients with COVID-19 infection. The Lancet Respiratory Medicine 2020.

6. Vergano M, Bertolini G, Giannini A, et al. Raccomandazioni di etica clinica per l'ammissione a trattamenti intensivi e per la loro sospensione, in condizioni eccezionali di squilibrio tra necessità e risorse disponibili. SIAARTI 2020. Available from: http://www.siaarti.it/SiteAssets/News/COVID19\%20-\%20 documenti\%20SIAARTI/SIAARTI\%20-\%20Covid19\%20$\% 20$ Raccomandazioni\%20di\%20etica\%20clinica.pdf 